\title{
UNDERSTANDING THE DYNAMICS OF LAND USE CHANGES: ASSESSMENT OF SUSTAINABLE LAND MANAGEMENT PROJECT SITES IN BHUTAN
}

\author{
*P. Gyeltshen, T. Dorji, D. Tashi, S. Pradhan, C. Tshering and T. Wangdi \\ National Soil Services Centre, Post Box No. 907, Semtokha, Thimphu, Bhutan. \\ *Corresponding Author
}

DOI: https://doi.org/10.51193/IJAER.2021.7306

\begin{abstract}
Land use (LU) assessment has been carried out at the sustainable land management (SLM) project sites in six Dzongkhags across Bhutan. This was done with an objective to provide baseline information of LU based on visual interpretation of LU classes and categories using Google Earth (GE) satellite image, coupled with extensive field verification. The results showed that the most dominant LU is dryland, constituting $63.33 \%$ of the total LU area, followed by irrigated wetland and horticulture combining to make $16.36 \%$ and $14.96 \%$ respectively. Interestingly, it was also revealed that $32.08 \%$ of the total LU area is abandoned dryland, which is $0.83 \%$ more than the cultivated dryland. Likewise, $4.61 \%$ of abandoned irrigated wetland is almost one third of total irrigated wetland area. In contrast, abandoned horticulture land category is less constituting only $1.02 \%$. There is a very strong positive corrrelation between the prevalence of abandoned agriculture land to the total area of the particular LU type. The results showed that the huge area of potential agricultural land remained idle or uncultivated. This may be closely attributed to various factors, including the prevailing socio-economic factors and impacts of climate change.
\end{abstract}

Keywords: Environmental, Land management, Land use, Socio-economic and Sustainable

\section{INTRODUCTION}

Land is one of the most vital resources on earth. It is needed for various purposes including agriculture, mining, forestry, infrastructure development, etc. Over the years, stress on agriculture land has been increasing. Expansion of urban areas, increased mining activities, building new road networks and other socio-economic activities put a lot of strain and stress on agriculture land. 
International Journal of Agriculture and Environmental Research

ISSN: 2455-6939

Volume: 07, Issue: 03 "May-June 2021"

Further, productive potential of land is lost due to degradation on annual basis (Lal, 2001). Today, how much land is actually available to grow crops sustainably is uncertain.

For Bhutan, the situation is even more precarious. This is because of the fact that only $9.70 \%$ of the total land area is cultivable. And more, actual cultivation occurs on $2.93 \%$ of the total land area, which generally comprises of gentle to moderately steep slopes. Yet, there are areas where cultivation occurs on very fragile and steep slopes (Norbu et al., 2003), even up to $40^{\circ}$ slope gradient (Gyeltshen, 2010). Where land is limited for agriculture, the most viable way forward is to make various attempts to manage the land resources in a sustainable manner. This is important to ensure continuous food production.

Various plans, programs and Chiwog ${ }^{1}$ level activities on land management are implemented across Bhutan in pursuit of the national and the UN sustainable development goals. One such activity is the Sustainable Land Management (SLM) Project that is currently being implemented in 18 Gewogs $^{2}$ spread across 6 Dzongkhags ${ }^{3}$ in Bhutan under the auspices of GEF/LDCF/SSCF Trust Funds. The project is a component of the major project tilted "Enhancing Sustainability and Climate Resilience of Forest and Agricultural Landscape and Community Livelihoods". It targets to achieve outcome number three of the parent project- "to make livelihood options for communities climate-resilient through diversification, SLM and climate-smart agriculture."

The goal of six years project (2018-2024) is to uplift the livelihood of communities and combat land degradation by implementing various SLM technologies. It targets to bring 2000 hectares (ha) of cultivated or abandoned agriculture land under SLM intervention by end of the project period.

For effective implementation, monitoring and impact assessment of project activities, the baseline data and information on the existing scenario of socio-economic status and land resources is vital. Indeed, the Land Use/Land Cover (LULC) map stands as primary baseline against which to compare future observed and recorded changes.

\section{MATERIALS AND METHODS}

Literature sources on digital and visual interpretation in relation to LULC mapping suggests that the accuracy of visual interpretation is generally equivalent, if not better than digital interpretation. Shirkou and Aliakbar (2013) concluded that "with regard to increasing desire among researchers for applying of GE imagery plus the capability of high spatial resolution and

\footnotetext{
${ }^{1}$ Smallest administrative unit under sub-district level

${ }^{2}$ Sub-administrative boundary within a District

${ }^{3}$ Literally translated as District
} 
free use, it could be considered as a reliable and valid source of data in LULC mapping and similar studies".

There are many other similar literatures which attest the relevancy of the visual interpretation with the help of GE satellite image. On this basis, the team adopted visual spatial image interpretation to develop LU map for aforementioned project sites. Smaller extent of project area was advantage over low time performance of this technique.

\subsection{Materials}

While preparing LU map, GE Pro software was used as visualization tool for image interpretation and on-screen digitization. The ancillary data, Bhutan Land Cover Assessment (LCMP 2010) and land parcel data (cadastral map) were used as base map. For data validation, AlpineQuest and hand held Garmin etrex Global Positioning System (GPS) were used to collect the reference data.

Arc GIS 10.3 was exclusively used for the preparation of land use layers, Geo-referencing and creation of spatial database.

\subsection{On-screen visual interpretation}

The LU image interpretation was done on high spatial resolution image of GE. Principally, the visual cues, such as tone, texture, size, shape, pattern, and relationship to other objects were used to carry out preliminary LU image classification. The supplementary ancillary data like cadastral map was overlaid on GE to integrate the classified information within the domain of such map to facilitate visual analysis and on-screen land use delineation. The tentative LU map was prepared with this technique.

\subsection{Field verification}

In order to counter the misleading errors resulting from the images and the maps generated from the visualization tools and other equipments, the detailed field verification in the form of participatory GIS was conducted at the Gewog level in all the Districts. On-site stakeholder representatives who had prior knowledge on LULC in their area were actively engaged in field verification. They were navigated through the tentative map on GE to make sure LU classes interpreted in the map correspond to ground reality. Of the average 50 participants partook in SLM sensitization workshop in every Gewog, five percent was involved compulsorily for map verification.

Depending upon their field knowledge, simultaneous error rectification on tentative map was performed. 


\subsection{Ground truthing}

Subsequent to field verification, ground truthing was carried out mainly in the places where there was low image resolution, dominant shadow effect and ambiguity in image patterns. To offset these impediments, field visits were arranged to observe the ground reality. The spatial location on the ground is linked to corresponding location in the map for necessary corrections or additions with regards to LU type in those particular places.

\subsection{Map processing}

For final map processing, the LU map was exported to ArcGIS 10.3. It was spatially referenced in DRUKREF-03 (Bhutan's Standard coordinate system, NLCS). Spatial analysis and statistics were carried out here to group, sort and screen LU classes. Figure 1 show the methodology flow chart involved in mapping.

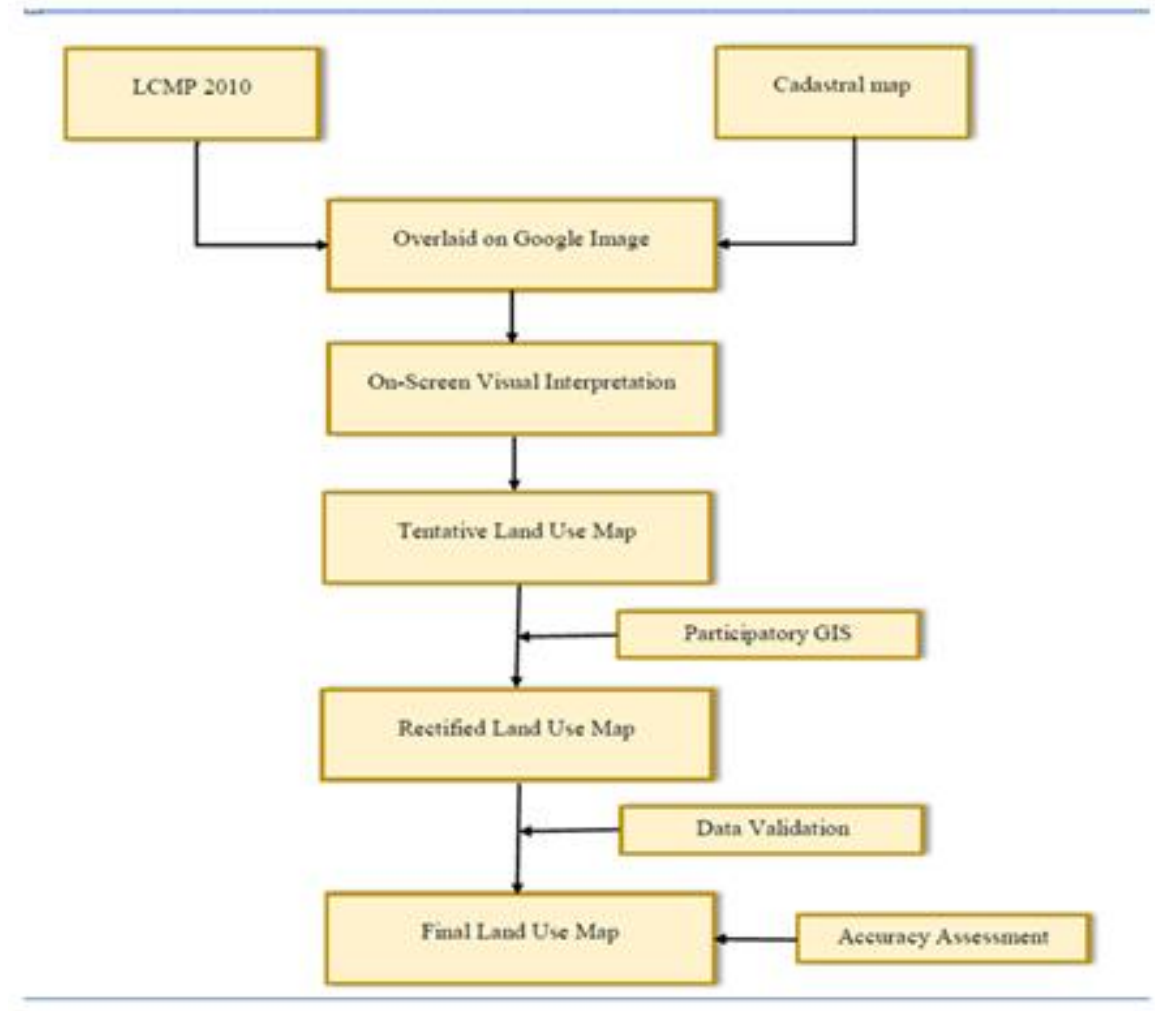

Figure 1: Methodology flow chart 


\subsection{Accuracy Assessment}

Analysis of error matrix or confusion matrix has been one of the common means of expressing classification accuracy of any maps. The main aim of accuracy assessment here is to quantitatively assess how effectively each pixel was sampled into correct land use classes. In doing so, the map generated through visual interpretation in vector format was rasterized to enable in carrying out the assessment. In order to adequately assess the accuracy of the final LU map, collection of accurate reference data was indispensable. A total of 500 reference points were randomly collected and logged in Alpine quest Mobile Apps which was later exported to Arc GIS compatible format to create the validation points. Furthermore Hand held etrex GPS were used to collect additional reference data.

Several descriptive measures were generated from the error matrix. The User accuracy which is the error of commission was measured using Equation (1) (aside), Producer accuracy also known as omission error was measured using Equation (2) and overall accuracy was computed using Equation (3) as indicated below.

The final LU map was subjected to Kappa statistics which is a measure of overall agreement of a matrix (Congalton, 1991).

User's accuracy $=\frac{\text { Total no of correct pixels }}{\text { Total no. of pixel classified in that category (Row total) }} \quad \mathrm{x} \quad 100$

Eq. (1)

Producer's accuracy $=\frac{\text { Total no of correct pixels }}{\text { Total no of pixel derievd from reference data (Column total) }} \quad \mathrm{x} \quad 100$ Eq. (2)

Overall accuracy $=\frac{\text { Total no of correctly classified pixels } \text { (Sum of the values in the main diagonal) }}{\text { Total number of pixels in the matrix }} \times 100$ Eq. (3)

Kappa was calculated using Equation (4)

Where;

$r=$ number of row and columns in error matrix

$$
\mathrm{K}=\frac{N \sum_{i=1}^{r} x_{i i}-\sum_{i-1}^{r}\left(x_{i}+X x_{+i}\right)}{N^{2}-\sum_{i=1}^{r}\left(x_{i i}+X x_{+i}\right)}
$$

$\mathrm{N}=$ total number of observations (pixels) 
$\mathrm{X}_{\mathrm{ii}}=$ number of observations in row $\mathrm{i}$ and column $\mathrm{i}$

$\mathrm{X}_{\mathrm{i+}}=$ marginal total of row $\mathrm{i}$, and $\mathrm{X}_{+\mathrm{i}}=$ marginal total of column $\mathrm{i}$

A kappa coefficient equal to 1 means perfect agreement while a value close to zero means that the agreement is no better than would be expected by chance. Interpretations of KAPPA coefficient is given in Table 1 below.

\section{Table 1: Interpretations of KAPPA coefficient}

\begin{tabular}{ll}
\hline KAPPA & Meaning \\
\hline$<0$ & No agreement \\
$0.01-0.02$ & Slight agreement \\
$0.21-0.04$ & Fair agreement \\
$0.41-0.06$ & Moderate agreement \\
$0.61-0.08$ & Substantial agreement \\
$0.81-1.00$ & Almost perfect agreement
\end{tabular}

\section{LU CLASSIFICATION SYSTEM}

The LCMP (2010) Land Cover Classification System was adopted to classify and map LU types in the project areas. Information related to forest, scrubs, shrubs and water bodies are not defined as the emphasis of the project intervention is exclusively on current land utilization.

The map was classified into three main LU classes with six sub-classes. Further, the sub-classes were divided into categories for more detailed mapping. The abandoned/ fallow agricultural land is also added as sub-classes in the LU map because significant proportion of potential agricultural land is found to have left fallow for different reasons. When mapped, it can be an indicator to determine projects achievement if and when SLM interventions like terracing, terrace consolidation, orchard basin making, and hedgerow establishment, etc. can encourage farmers to revive farming in the present fallow lands. The breakdown of LU classes, sub-classes and categories are presented Table 2 . 
International Journal of Agriculture and Environmental Research

ISSN: 2455-6939

Volume: 07, Issue: 03 "May-June 2021"

Table 2: LU classes, sub-classes and categories

\begin{tabular}{|c|c|c|c|}
\hline Class & Sub-Class & Category & Symbol \\
\hline \multirow{2}{*}{ Chhuzhing (irrigated land) } & Cultivated chhuzhing & & $\mathrm{AC}$ \\
\hline & Abandoned chhuzhing & & $\mathrm{AbAC}$ \\
\hline \multirow{2}{*}{ Kamzhing (dry land) } & Cultivatedkamzhing & & $\overline{\mathrm{AK}}$ \\
\hline & Abandonedkamzhing & & $\mathrm{AbAK}$ \\
\hline \multirow{5}{*}{ Horticultural land } & & Apple orchard & HA \\
\hline & Gultivated horticulture land & Citrus orchard & $\mathrm{HC}$ \\
\hline & & Cardamomplantation & $\mathrm{HCo}$ \\
\hline & & Others & но \\
\hline & Abandoned horticulture land & & $\mathrm{AbH}$ \\
\hline Build up areas & & & $\mathrm{BA}$ \\
\hline
\end{tabular}

The LU classes depicted broadly in the above table are elaborated below.

\subsection{Cultivated Agricultural Land}

The cultivated agricultural land includes only those agricultural land that are cultivated at the time of LU classification assessment. It is divided into three main sub-classes viz. chhuzhing, kamzhing and horticulture land.

Chhuzhing land (AC): The "chhuzhing land" refers to bench terraced agricultural land that is usually used for irrigated paddy rice cultivation. The terraced paddy fields are usually inundated in some part of the year through retention of rain water or through irrigation.

Kamzhing land (AK): The "kamzhing land" refers to cultivated rain-fed areas (dryland). Some Kamzhing lands have certain level of land shaping.

Horticulture land: The "horticulture land" includes orchards and plantation of cash crops. It is further divided into four sub-classes viz. Apple orchard; Citrus orchard; Cardamom plantations and Others.

a) Apple Orchard (HA): This category includes areas under apple trees and occurs usually between $1800 \mathrm{~m}$ to 2600 masl. 
b) Citrus Orchard (HC): This category includes areas under citrus (orange) trees. It is normally located between $400 \mathrm{~m}$ to 1400 masl.

c) Cardamom Plantation (HCo): This category includes cardamom plantation in the open field or beneath the trees and shrubs establishment.

d) Others (HO): This category includes areas under mixed fruit trees or very small scale plantations of different horticulture crops beside apple, citrus and cardamom.

\subsection{Abandoned Agricultural Land}

Abandoned kamzhing (AbAK), chuzhing (AbAC) and horticulture land $(\mathrm{AbH})$ are the fields that are left fallow/uncultivated at the time of LU mapping, but were used for cultivation in the past.

\subsection{Built up Areas (BA)}

This category describes built-up areas where artificial constructions cover the land with an impervious (e.g. concrete, CGI sheet, thatch) surface. It includes rural settlements, urban areas, schools, institutes, industrial areas and hospital premises.

\section{RESULTS}

\subsection{General LU findings}

The Figure 2 shows the percentage of area under four major LU types. The most dominant LU is kamzhing and it constitutes more than half $(63.33 \%)$ of the total LU area. The chhuzhing and horticulture combined makes up approximately about $30 \%$ of the total LU area covering $16.36 \%$ and $14.96 \%$ respectively while, built up land represents only $5.56 \%$. 


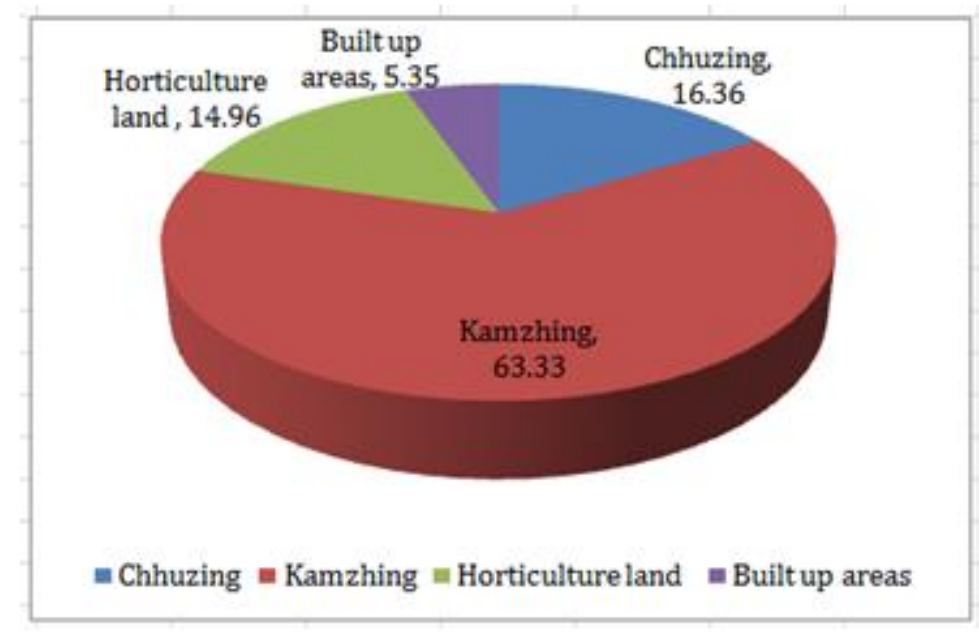

Figure 2: Percentage area under fur major LU types

The Figure 3 shows the detail LU percentage for all the LU categories. Though, kamzhing constitutes $63.33 \%$ of LU area, surprisingly, more than half (31.25\%) of the area is abandoned kamzhing in which the land remains uncultivated for some years to many years. The prevalence of land remaining fallow is the prominent issue in all the project areas driven by various factors; social, economy and environmental conditions. Similarly, about one third of the chhuzhing is also left uncultivated mainly due to shortage of irrigation water, labour and other related problems.

For $14.96 \%$ of horticulture land; apple, citrus and cardamom constitutes $0.17 \%, 4.59 \%$ and $8.63 \%$ respectively, while other fruit crops which constitute $0.55 \%$ are put under one category due to small area under plantation. The abandoned horticulture land is less as compared to chhuzhing and kamzhing. It constitutes only $1.02 \%$ of the total LU area. 


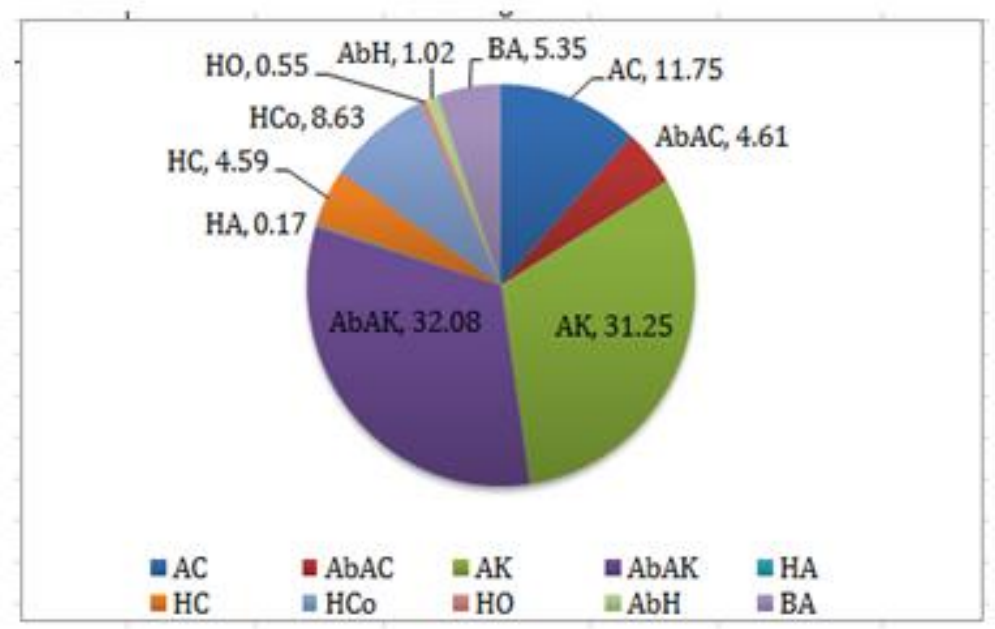

Figure 3: Composition of different LU classes and categories in \%

\subsection{Dzongkhag level LU findings}

In Haa, the most dominant LU is kamzhing occupying an area of 3034.20 ac of land followed by 1218.25 ac of cardamom plantation. Though, kamzhing is very extensive, about $1448.43 \mathrm{ac}$ is abandoned kamzhing which is approximately half of the total kamzing area. The area under other horticulture crop is least constituting just 32.59 ac of land.

In Lhuentse, kamzhing covers $72.05 \%$ of the total LU area of the Dzongkhag and of this $1847.04 \mathrm{ac}$ is cultivated and $1421.42 \mathrm{ac}$ is uncultivated land. Similarly, 637.86 ac chhuzhing is in active cultivation and $302.11 \mathrm{ac}$ is left uncultivated.

Over $80 \%$ of the land in Mongar is also under kamzhing and of that 1907.96 ac is cultivated and $1152.81 \mathrm{ac}$ is abandoned. Horticulture crops occupy least area covering a combined area of just 173.64 ac.

The trend is same with Sarpang where the most dominant LU is kamzhing with an area of 3483.11 ac. The marked contrast to other Dzongkhags is that, comparatively, the proportion of abandoned chhuzhing and kamzhing is considerably low with respect to the total LU area but the abandoned horticultural land area is highest with 292.56 ac.

The area of abandoned kamzhing $(3677.73$ ac) is almost double the area of cultivated kamzhing $(1832.17 \mathrm{ac})$ in Trongsa. About quarter the total LU area of the Dzonkhag is chhuzhing. It constitutes $18.62 \%$ cultivated and $6.02 \%$ abandoned land. Only $6.55 \%$ of the LU area is used for growing horticultural crops and cardamom is the most widely grown horticulture crop. 
The project site in Zhemgang encompasses the highest total land use area accounting to 10910.69 ac. However, $47.1 \%$ land is left fallow under kamzhing (40.86\%), chhuzhing (5.73\%) and horticulture $(0.51 \%)$ land category.

About $26.60 \%$ and $10.16 \%$ land is under active dryland and irrigated crop cultivation respectively. Citrus is the most widely grown horticultural crop. Table 4 shows the area of each LU categories in different Dzongkhags.

\begin{tabular}{|l|c|c|c|c|c|c|c|}
\hline & Haa & Lhuents & Mongar & Sarpang & Trongsa & Zhemgang & Total area \\
\cline { 2 - 10 } & Land use Areas in acre & & & & \\
\hline AC & 95.09 & 637.86 & 202.32 & 1091.47 & 1636.59 & 1108.07 & 4771.41 \\
\hline AbAC & 57.70 & 302.11 & 30.93 & 327.05 & 528.82 & 625.12 & 1871.73 \\
\hline AK & 1585.72 & 1847.04 & 1907.96 & 2612.68 & 1832.17 & 2902.46 & 12688.08 \\
\hline AbAK & 1448.43 & 1421.42 & 1152.81 & 870.43 & 3677.73 & 4458.01 & 13028.83 \\
\hline HA & 66.86 & 0 & 0 & 1.87 & 0 & 0 & 68.73 \\
\hline HC & 123.90 & 16.55 & 61.45 & 626.22 & 31.76 & 1002.03 & 1861.91 \\
\hline HCo & 1218.25 & 15.70 & 70.64 & 1504.66 & 544.09 & 150.95 & 3504.29 \\
\hline HO & 32.59 & 96.97 & 41.55 & 0 & 0 & 52.02 & 223.13 \\
\hline AbH & 15.25 & 0 & 0 & 292.56 & 51.90 & 55.92 & 415.63 \\
\hline BA & 388.87 & 198.74 & 352.73 & 191.97 & 485.77 & 556.11 & 2174.19 \\
\hline Total & 5032.72 & 4536.39 & 3820.39 & 7518.91 & 8788.83 & 10910.69 & 40607.93 \\
\hline & & & & & & & \\
\hline
\end{tabular}

\section{Table 3: Area of each land use category in different Dzongkhags}

\subsection{Gewog level LU findings}

\section{a. Chhuzhing:}

Jigme Chhoeling Gewog constitutes the highest cultivated and abandoned chhuzhing with an area of 727.10 ac and 308.10 ac respectively. The second highest area of cultivated chhuzhing is in Langthil and abandoned chhuzhing is in Nangkor Gewog. For most of the Gewogs, the proportion of chhuzhing kept uncultivated is almost equal or slightly higher than the half of the cultivated chhuzhing.

However, Nubi, Saling and Chhudzom Gewogs have utilized $88.23 \%$ to $95.06 \%$ of their chhuzing for cultivation. In contrary, Tsamang is the only Gewog where abandoned chhuzhing is more than the cultivated chhuzhing extending up to $71.19 \%$ of the total chhuzhing in the Gewog. 
On the contrary to others, less than 2 ac of land is under chhuzhing LU in Samar Gewog and this is the lowest of all the sites. The Figure 4 shows the detail information about the chhuzhing LU in each site.

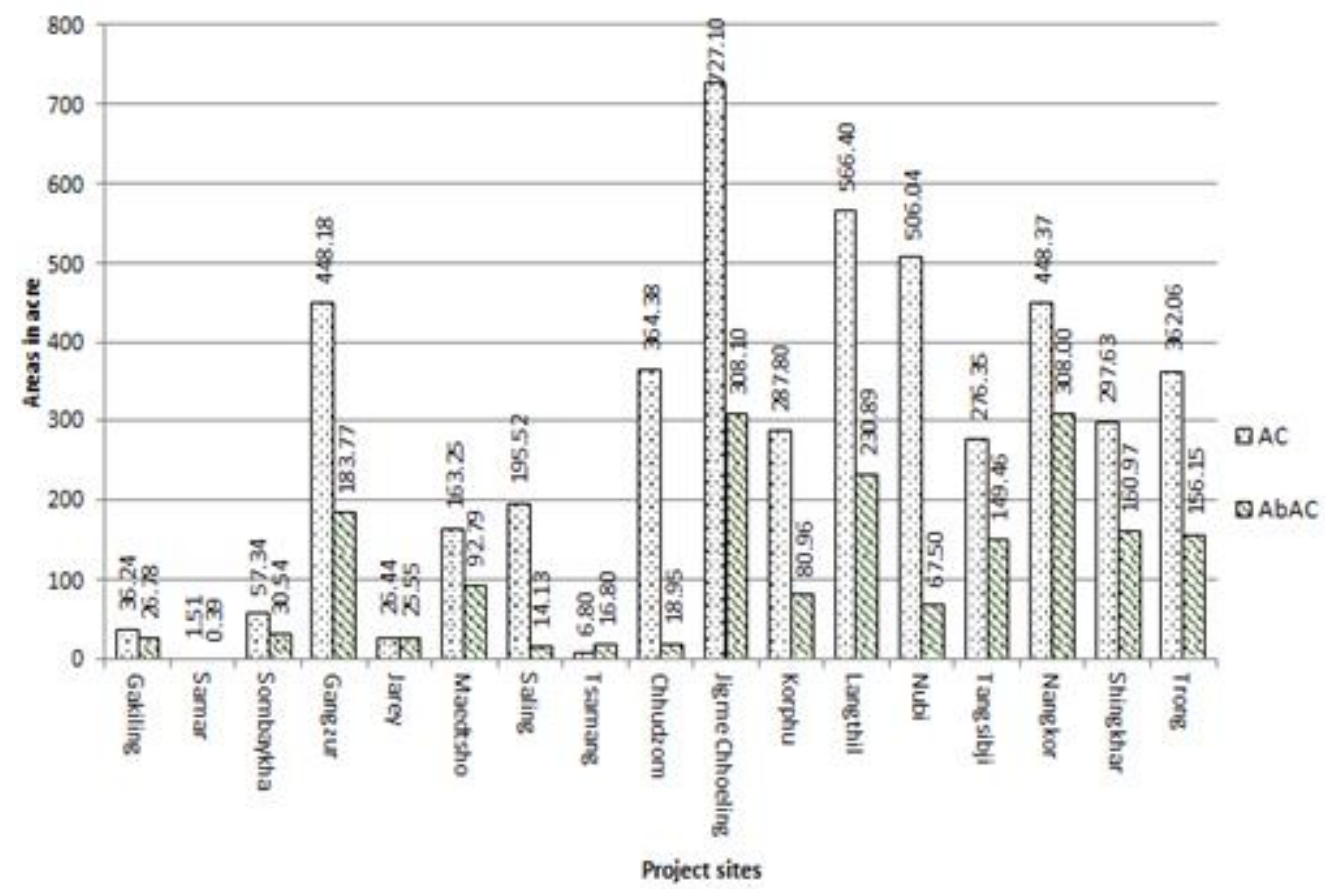

Figure 4: Area of cultivated and abandoned chhuzhing in the Gewogs

\section{b. Kamzhing:}

Nangkor Gewog encompasses the maximum area of kamzhing land. Of that, approximately two third (1977.68 ac) of land is left uncultivated which is the highest area under abandoned kamzhing LU type when compared to other sites. Chhudzom Gewog dominates in kamzhing land utilization due to which abandoned kamzhing area is relatively smaller with respect to the total kamzhing LU area of the Gewog.

Gakiling and Sombaykha Gewogs in Haa and all the Gewogs in Trongsa and Zhemgang comprise higher area of abandoned land than the cultivated land. The cultivated land in Korphu Gewog is only about $20 \%$ of the total kamzhing land in the Gewog.

The least area of kamzhing is in Samar and Sombaykha which are under Haa Dzongkhag. Figure 5 shows the detail information about the kamzhing LU in each site. 
International Journal of Agriculture and Environmental Research

ISSN: 2455-6939

Volume: 07, Issue: 03 "May-June 2021"

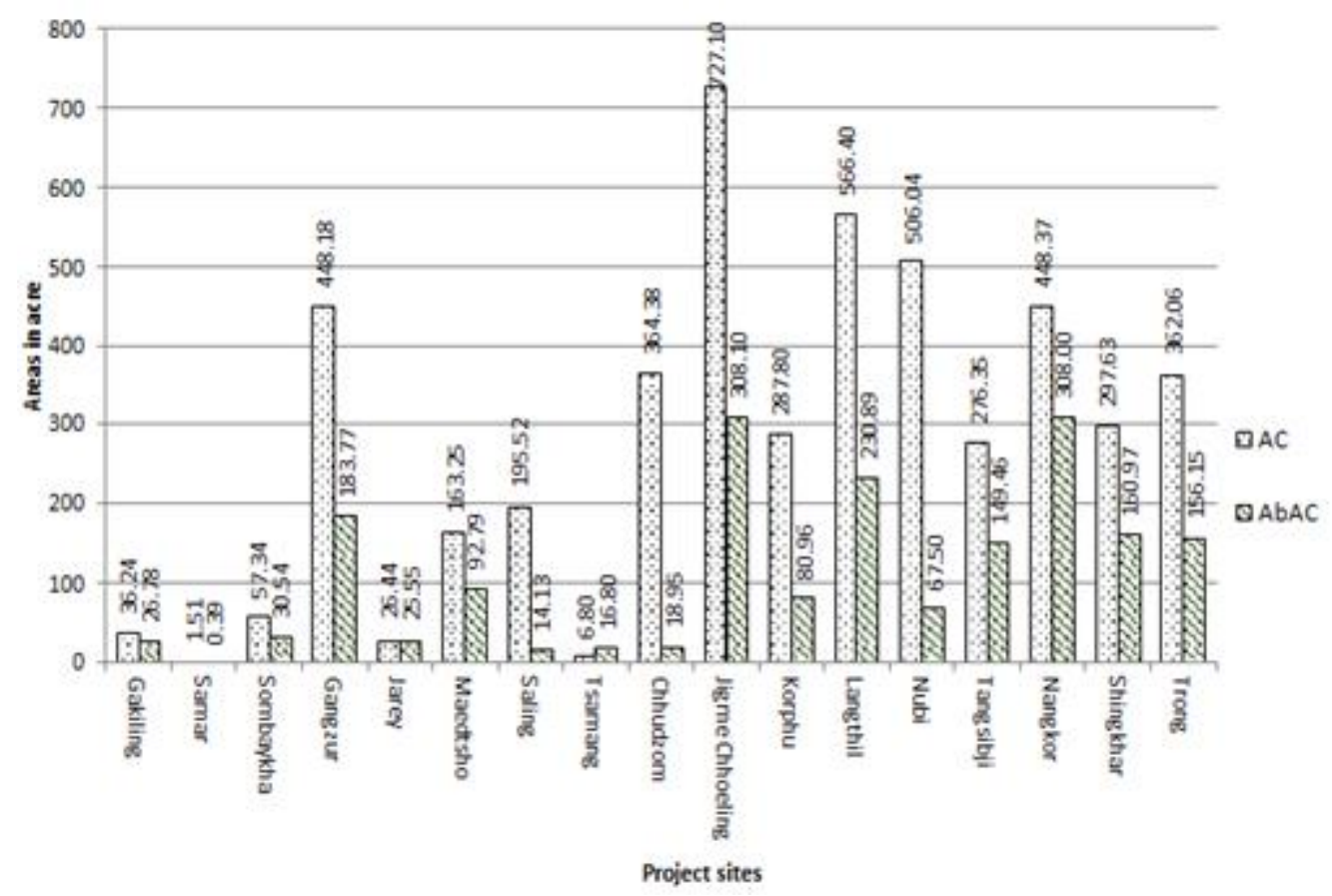

Figure 5: Area of cultivated land and abandoned kamzhing in the Gewogs

\section{c. Horticulture land:}

The most common horticulture crop grown in the project sites is cardamom followed by citrus. Area under cardamom plantation is highest in Sarpang in which Jigmecholing Gewog alone covers an area of 1109.29 ac and Chuzom with 395.37 ac of land. In Haa, Sombaykha and Gakiling Gewogs are hotspot for cardamom cultivation spreading over 481.66 ac and 736.59 ac respectively. Similarly, Korphu is the main Gewog in Trongsa where cardamom plantation is widely carried out.

Citrus orchard is extensive in Zhemgang which is grown predominantly in Nagkhor (309.99 ac) and Trong (692.04 ac), likewise, Jigmecholing (600.37 ac) in Sarpang and Gakiling (104.66 ac) in Haa.

Apple is grown dominantly in Haa, particularly in Bji (26.17 ac) and Samar (40.59 ac) Gewogs, whereas, other horticultural crops besides cardamom, citrus and apple is grown commonly in Lhuentse Gewogs especially in Gangzur and Maedtsho.

Abandoned horticulture land is also noticeably most prominent in Jigme Chhoeling and Chhudzom in Sarpang Dzongkhag. Figure 6 shows the detail information about horticulture LU in each site. 


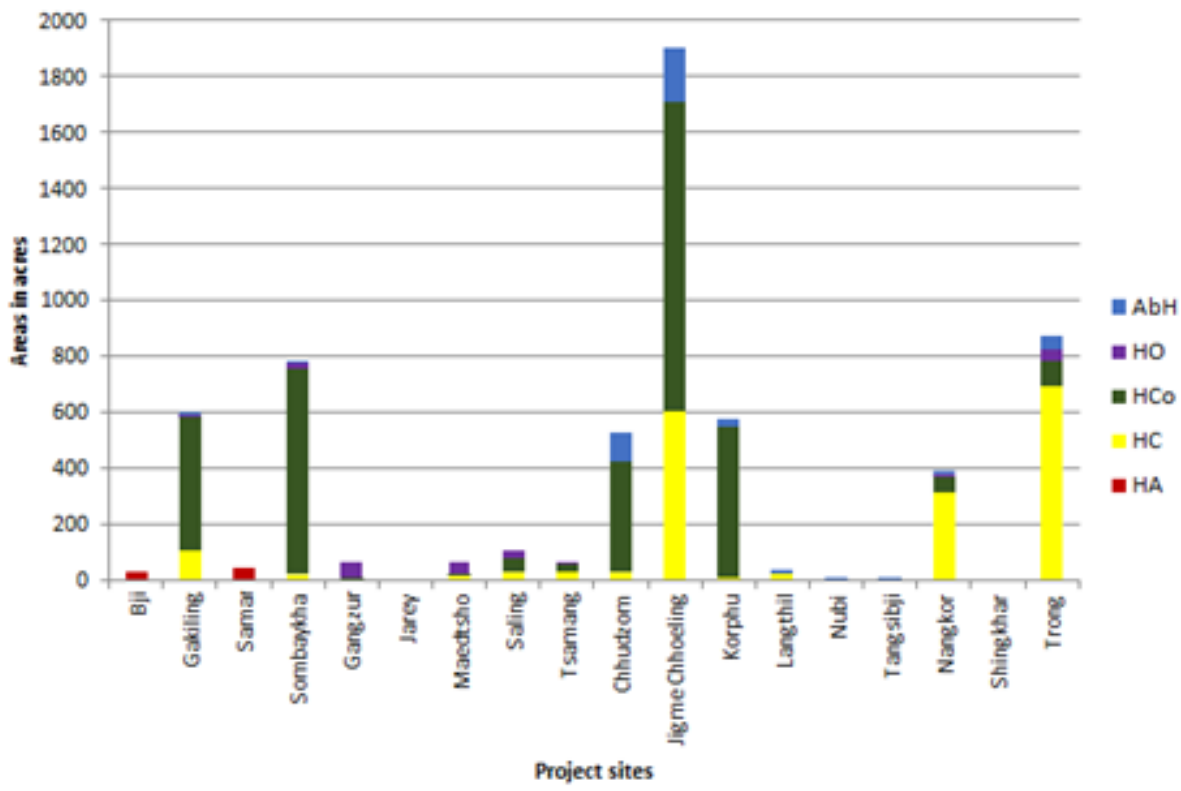

Figure 6: Area of Horticultural LU for different fruit crops and plantations

\section{d. Built up areas}

The LU for residential, institutional, commercial and industrial purposes is highest in Trong Gewog in Zhemgang followed by Saling in Mongar. In most of the Gewogs, land utilized for built up areas is below 150 ac. Just about 35 ac of land is allotted for built up in Gakiling and Korphu under Haa and Trongsa Dzongkhags respectively- Refer Figure 7. 


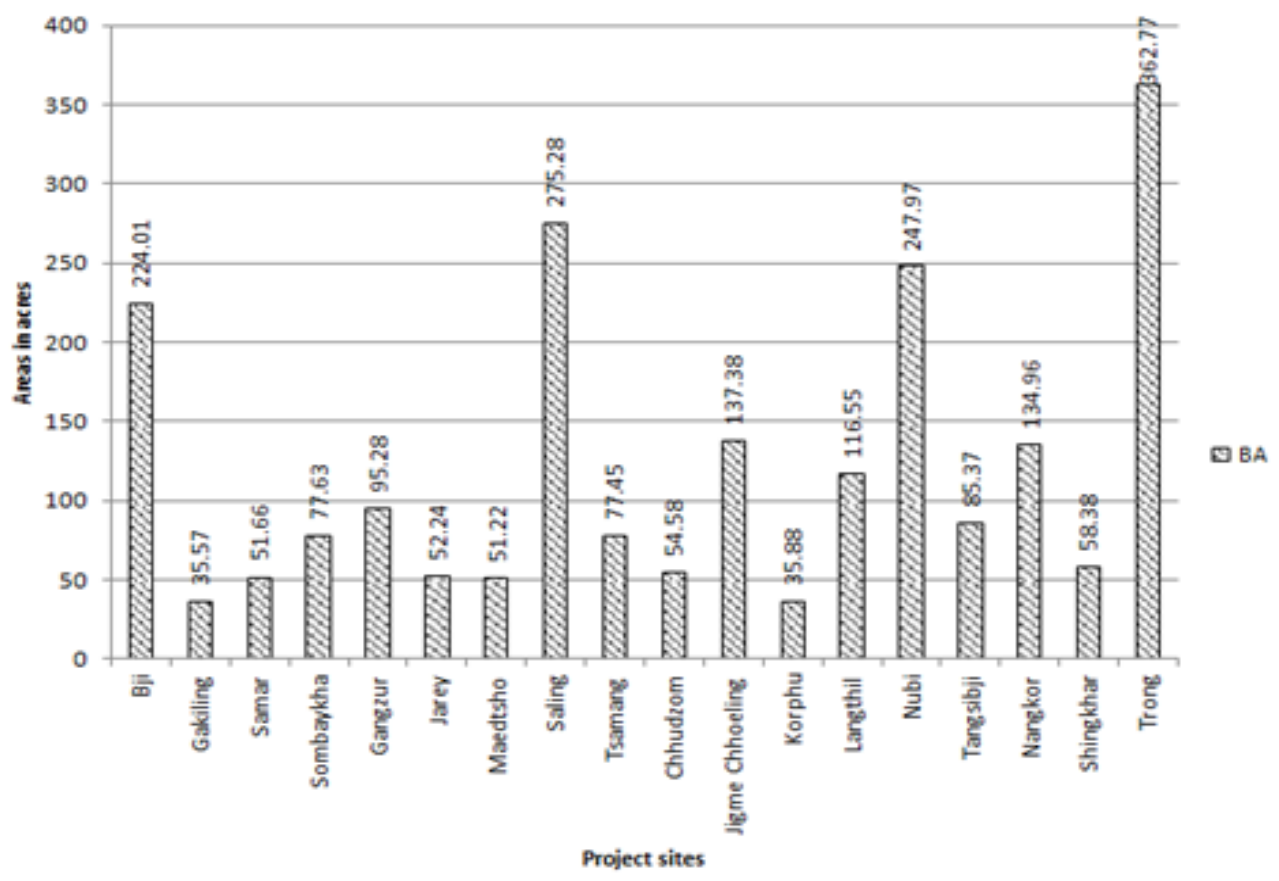

Figure 7: Built up areas in the Gewogs

The mappings for all project sites are carried out separately between the scales of 1:10000 to 1:20000 based on the LU area of each site. Refer Appendix 1 for Bji, in $\mathrm{Ha}$ and Gangzur, in Lhuentse, LU maps as an example.

\subsection{Accuracy Assessment}

An error matrix was generated to evaluate the accuracy of map generated through participatory GIS techniques. According to Congalton and Green (1999) the error matrix is defined as a square array of numbers of sample units (pixels, cluster of pixels or polygons) assigned to a particular class relative to actual land cover class. In other words it is a table that displays statistics for assessing image classification accuracy by showing the degree of misclassification. In this report, the LU map generated by above means was compared with the reference data set.

Based on the error matrix, statistical analysis including overall accuracy (percentage of correctly classified pixels on the map), producer's accuracy (probability of classes that was classified correctly), user's accuracy (probability that a pixel classified corresponds to the real ground), and KAPPA (measurement of correspondence between data obtained from analysis and reference data) were performed. 
The result presented in Table 4 shows that the map generated through participatory GIS techniques yielded a satisfactory result with KAPPA coefficient of 0.9244 and overall accuracy of $93.20 \%$. This means the agreement between the land use map generated through aforementioned techniques and the reference data represents strong agreement. According to Landis and Koch (1997) a KAPPA value greater than 0.81 represents almost perfect agreements. Both the user's and producer's accuracies are in general high (greater than $85 \%$ ) for every land use classes except for AK (Kamzhing). The user's and producer's accuracies were $86.0 \%$ and $74.10 \%$ respectively. This means that $86.0 \%$ of the actual land use classed as "AK" were correctly classified, but only $74.10 \%$ of areas classified as "AK" corresponds to same class on the real ground. Over all the result indicates that relatively good LU map could be generated by means of above mentioned techniques. Confusion of classes is obvious in all the LU classes with user's accuracies ranging from $86 \%$ to $98 \%$. This revealed that only $86 \%-98 \%$ are correctly classified on the map.

Table 4: Confusion matrix of LU map generated through participatory GIS techniques

\begin{tabular}{|c|c|c|c|c|c|c|c|c|c|c|c|c|}
\hline $\begin{array}{c}\text { Classification } \\
\text { result from } \\
\text { LU map }\end{array}$ & 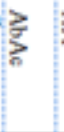 & $\stackrel{\mp}{>}$ & 多 & $\underset{z}{z}$ & z & วิ & 齐 & 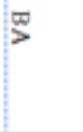 & รั & ธَ & $\vec{e}$ & कृ \\
\hline $\mathrm{AbAC}$ & 49 & 0 & 0 & 0 & 1 & 0 & 0 & 0 & 0 & 0 & 50 & 98.0 \\
\hline HA & 0 & 48 & 0 & 0 & 0 & 0 & 2 & 0 & 0 & 0 & 50 & 96.0 \\
\hline AbAK & 0 & 0 & 48 & 0 & 0 & 0 & 0 & 0 & 0 & 2 & 50 & 96.0 \\
\hline $\mathrm{AbH}$ & 0 & 0 & 0 & 49 & 0 & 0 & 0 & 0 & 1 & 0 & 50 & 98.0 \\
\hline $\mathrm{AC}$ & 1 & 0 & 0 & 0 & 46 & 0 & 3 & 0 & 0 & 0 & 50 & 92.0 \\
\hline $\mathrm{HCO}$ & 0 & 0 & 2 & 0 & 0 & 46 & 1 & 1 & 0 & 0 & 50 & 92.0 \\
\hline $\mathrm{AK}$ & 0 & 0 & 3 & 0 & 0 & 1 & 43 & 1 & 1 & 1 & 50 & 86.0 \\
\hline $\mathrm{BA}$ & 0 & 0 & 0 & 0 & 0 & 0 & 2 & 48 & 0 & 0 & 50 & 96.0 \\
\hline $\mathrm{HC}$ & 0 & 0 & 1 & 0 & 0 & 0 & 4 & 0 & 43 & 0 & 50 & 90.0 \\
\hline HO & 0 & 0 & 1 & 0 & 0 & 1 & 3 & 0 & 1 & 44 & 50 & 88.0 \\
\hline Total & 50 & 48 & 55 & 49 & 47 & 48 & 58 & 50 & 48 & 47 & 500 & \\
\hline $\begin{array}{l}\text { Prodacer's } \\
\text { accuracy }(\%)\end{array}$ & 98.0 & 100 & 87.3 & 100 & 97.9 & 95.8 & 74.1 & 96.0 & 93.8 & 93.6 & & \\
\hline \multicolumn{13}{|c|}{ Overall accuracy $=93.2 \% ; \mathrm{KAPA}=0.92$} \\
\hline
\end{tabular}

\section{DISCUSSION}

Land resources are scarce, but the contrast is, agriculture production has to gain positive progression in order to feed the growing population. Here, one thing to be concerned about is the reduced agriculture production When society undergoes some kind of drastic socio-economic 
International Journal of Agriculture and Environmental Research

ISSN: 2455-6939

Volume: 07, Issue: 03 "May-June 2021"

changes (Easterling \& Apps, 2005), land degradation problems creep in. True to saying that land degradation issues are partly socially constructed, both locally and at broader scales, (Lestrelin \& Giordano, 2007), developmental activities in any form(s) may contribute to causing land degradation (Veznia et al., 2006). All of these demands the need to plan the land resource use in a more systematic and practical way.

The exercise of creating LU map at the Gewog level in the eighteen chosen Gewogs was initiated with the help of SLM project funded by GEF LDCF. This assessment is meant to be an important reference document for on-going planning and formulation of program priorities and implementation approaches of SLM interventions in Bhutan. Basically, it would steer the efficiency of planners and stakeholders to increase agricultural productivity and initiate environmentally sustainable activities in the project sites and beyond. Further, it will serve as a baseline document for monitoring and/or tracking of project progress and its eventual impacts at a later stage and in the aftermath of the project completion.

What has unfolded is that the kamzhing is the main LU type in the project sites constituting $63.33 \%$ of the total LU area. Of that, more than half of the potential land is left fallow, which is a grave concern particularly in light of the fact the average Bhutanese farmers own very small land parcels in the villages (Gyeltshen, 2010), and the fact that the physical land degradation is mainly triggered by fallowing land parcels (Harden, 1996), and the worse is that most of the agriculture land in Bhutan is on steep slopes (. This finding should be considered and adopted seriously by the project implementers to target these areas for SLM backstopping to ultimately encourage farmers to revive the cultivation. On top of that, more information may be gathered to find out and to understand why farmers are leaving their land fallow. This may be partly attributed to the changes in the socio-economic dynamics that is sweeping across Bhutan (NSB, 2020), crop depredation by wild animals (Wang et al., 2006) and climate related factors (Chhogyel \& Kumar, 2018; Chhogyel et al., 2020). To bring back such fallow land back under cultivation, identifying what SLM technologies would suit best based on environmental conditions and community priorities to enhance crop production and combat physical land degradation that is currently prevailing in Bhutan (Gyeltshen, 2010; NSSC, 2005).

The second most popular LU is chhuzhing at $16.36 \%$. However, it is again disappointing that approximately one fourth of the chhuzhing is also left uncultivated. In this case, project support should also focus in providing technical assistance and resources (infrastructure) within the domain of SLM to motivate farmers. This would help increase their efforts in paddy cultivation and in turn deter them from leaving the land fallow. Here, the most common obstacles related to abandonment of chhuzhing are scarcity of irrigation water, shortage of labour and drudgery. To 
International Journal of Agriculture and Environmental Research

ISSN: 2455-6939

Volume: 07, Issue: 03 "May-June 2021"

counter these issues, terrace consolidation activities need to be supported to widen the terrace width and facilitate farm mechanization.

The horticultural crops such as apple, citrus and cardamom are the main income generator in the project sites. Proper orchard management through introduction of appropriate management techniques for such crops need to be prioritized to ensure that the farming is profitable and it sustains the livelihood of the farmers.

It would be vital to integrate results of this mapping exercise into participatory planning processes in the communities, decision making and implementation with prior knowledge on the status of current LU. This would reinforce the capacity of local community in developing a detailed LU management plans. Although, different LU categories existed in the farming systems, abandoning potential agriculture land is common and is an ongoing trend. This, in fact is a progressive decline in agriculture. Quite clearly, farmers are not so alarmed about it. Sensitization with empirical evidences of overall data on LU of their own region would at least make them aware of pressing issues on land remaining fallow.

\section{CONCLUSION}

With fast changing socio-economic dynamics and environmental attributes land is continuously put under lots of stress and strain. This is mainly because, farmers have to cultivate land to produce adequate to meet the demands of the growing population. So, when land resource is scarce for cultivation, this would put society on edge.

Land use assessment is a prerequisite to properly manage land resources through placement of appropriate sustainable land management technologies.

The land use assessment exercise that was carried out in the six Dzongkhags mapped the proportion of kamzhing, chhuzhing and horticulture land in the sustainable land management project areas. An interesting feature of this exercise is the discovery of significant fallow land in varying proportions. This is a real concern because Bhutan already has limited land available for agriculture. And despite increasing population on annual basis, corresponding increase in food production has not taken place.

The land use maps could serve as a vital tool and a source of baseline information while planning the future activities in different areas of sustainable management could be helpful while considering the type of land management technologies to be placed and in projecting the financial budget that is required for the activity. This would lead to fair distribution of the budgets, placement of more appropriate land management technologies considering the sitespecific attributes and an increased food production. 
International Journal of Agriculture and Environmental Research

ISSN: 2455-6939

Volume: 07, Issue: 03 "May-June 2021"

\section{REFERENCES}

Chhogyel, N., Kumar, L and Bajgai, Y. Consequences of Climate Change Impacts and Incidences of Extreme Weather Events in Relation to Crop Production in Bhutan, Sustainability 2020, 12, 4319 (2020)

Chhogyel, N., Kumar, L. Climate change and potential impacts on agriculture in Bhutan: a discussion of pertinent issues. Agric \& Food Secur 7, 79 (2018)

Congalton, R.G. A review of assessing the accuracy of classifications of remotely sensed data. Remote sensing of environment. 37(1): 35-46 (1991)

Easterling, W and Apps, M. Assessing the consequences of climate change for food and forest resources, a view from the IPCC. Climate Change, 70,165-189 (2005)

Congalton, R.G. and Green, K. Assessing the Accuracy of Remotely- Sensed Data: Principles and Practices. Lewis Publishers, CRC press, USA (1999)

Gyeltshen, P. The Dynamics of Socio-economic Situations of Communities in Relation to Land Degradations- Bhutan, MSc Thesis, Wageningen University, The Netherlands (2010).

Harden, C.P. Interrelationships between land abandonment and land degradation: a case from the Ecuadorian Andes. Mountain Research and Development, 16(3)274-280 (1996).

Lal, R. Soil degradation by erosion. Land degradation and development. 12, $519-539$ (2001).

Landis, J. and Koch, G. The measurement of observer agreement for categorical data. Biometrics. 33: 159-174 (1977)

Lestrelin, T.L and Giordano, M. Upland development policy, livelihood change and land degradation: Interaction from a Loatian Village. Land Degradation and Development, 18, 55-76 (2007)

Norbu, C., Baillie, I., Dema, K., Dema., Y., Tamang, H.B., Turkelboom, F. Types of land degradation in Bhutan, Journal of Bhutan Studies, 8, 88-140 (2003)

NSB, SYB. Statistical Year Book, National Statistics Bureau, Butan (2020)

NSSC. Assessment of Land Degradation in Bhutan, National Soil Services Centre, Ministry of Agriculture and Forests, Bhutan (2005)

NSSC, LCMP. Bhutan Land Cover Assessment 2010. A Technical Report. National Soil Services Centre (NSSC), Ministry of Agriculture \& Forests, Bhutan (2010) 
Shirkou, J. and Nazarisamani, A. Comparison between Land Use and Land Cover Mapping through Land sat and Google Earth Imagery. American - Eurasian J. Agric. \& Environ. Sci., 13 (6): 763 - 768 (2013)

Vezina, K., Bonn, F. and Van, C.P. Agriculture land use patterns and soil erosion vulnerability of watershed units in Vietnam's northern highlands. Landscape Ecology, 21, 1311-1325 (2006)

Wang, S.W., Curtis, P.D and Lassoie, J.P. Farmer Perceptions of Crop Damage by Wildlife in Jigme Singye Wangchuk National Park, Bhutan; Wildlife Society Bulletin, Vol.34, No. 2 (359-365)- 2006

\section{APPENDIX 1: Land use map of Bji and Gangzur Gewogs}

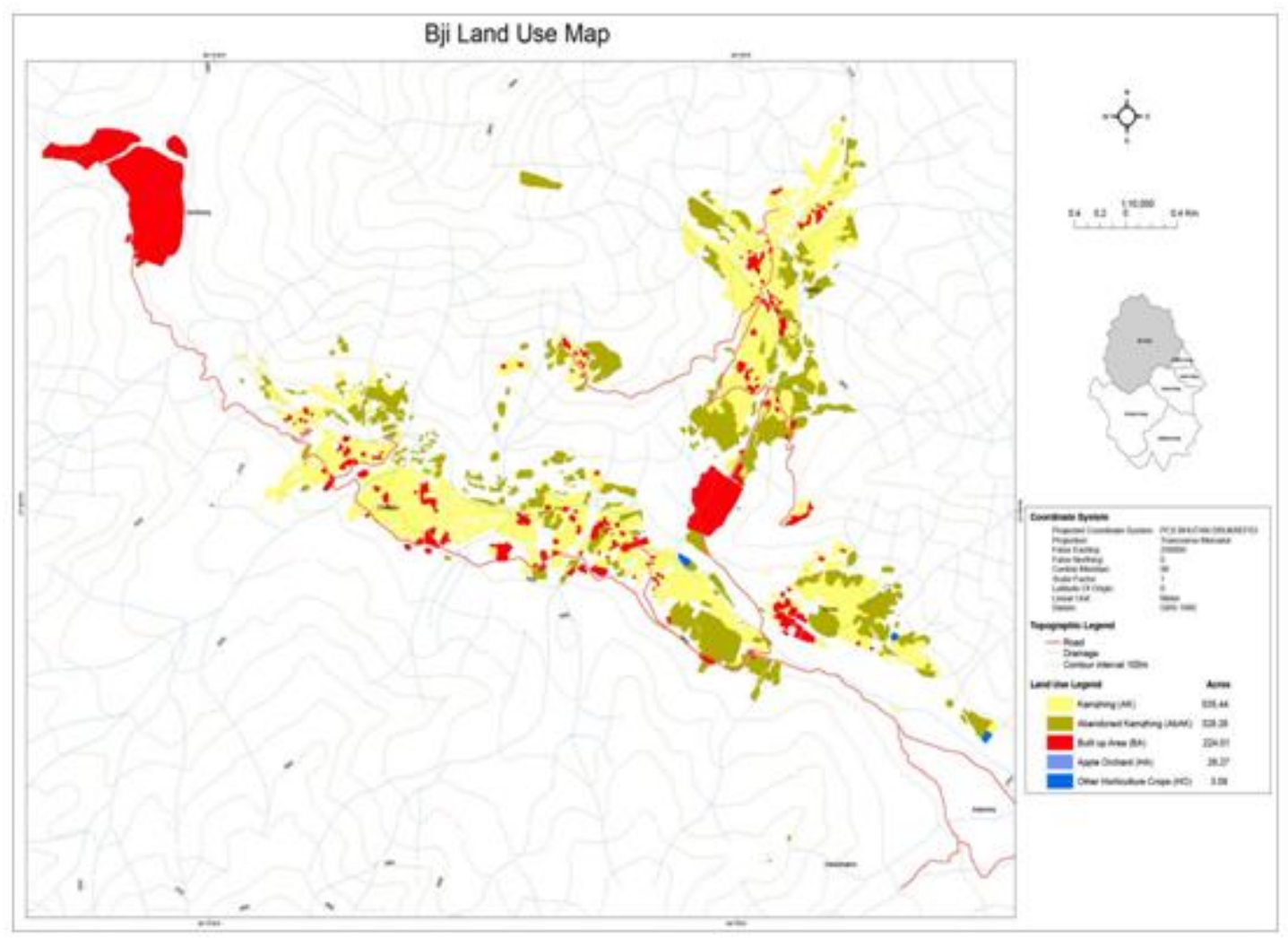


International Journal of Agriculture and Environmental Research

ISSN: 2455-6939

Volume: 07, Issue: 03 "May-June 2021"

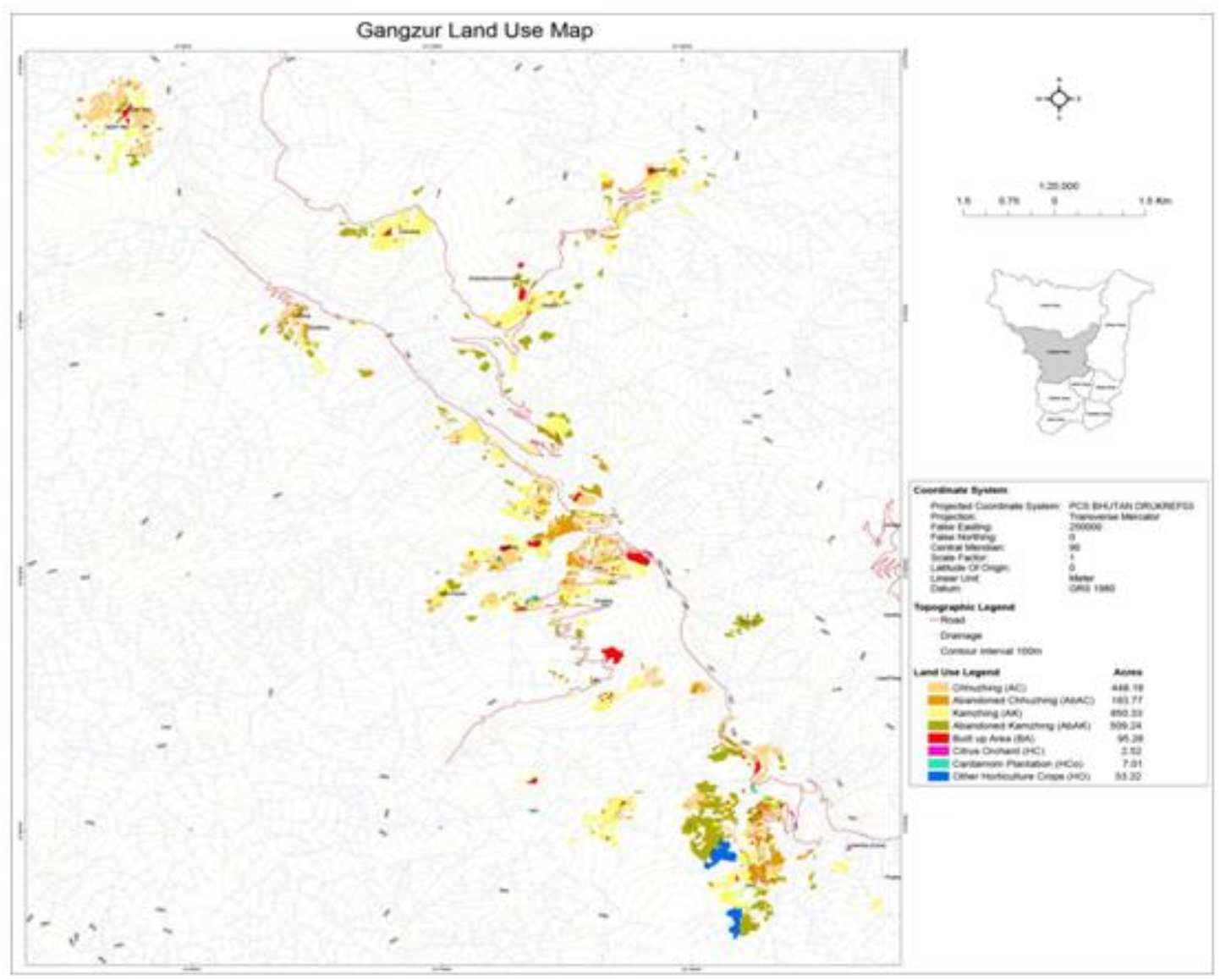

